\title{
Prevalence of ectoparasite infestations of cattle in Bench Maji zone, southwest Ethiopia
}

\author{
Simeon Haile Onu and Tesfaheywet Zeryehun Shiferaw \\ College of Veterinary Medicine, \\ Haramaya University, P.O.Box 138, Dire Dawa, Ethiopia. \\ Corresponding author: Tesfaheywet Zeryehun Shiferaw, email:tesfahiwotzerihun@yahoo.com \\ Received: 11-09-2012, Accepted: 31-10-2012, Published online: 25-02-2013
}

\section{How to cite this article:}

Onu SH and Shiferaw TZ (2013) Prevalence of ectoparasite infestations of cattle in Bench Maji zone, southwest Ethiopia, Vet. World 6(6): 291-294, doi: 10.5455/vetworld.2013.291-294

\begin{abstract}
Aim: This study was conducted with the aim of determining the prevalence and type of ectoparasitic fauna and associated host-related risk factors in cattle in Bench Maji Zone, Southwestern, Ethiopia, from October 2011 to April 2012.

Materials and Methods: A total of 212 cattle (84 male and 128 female) were sampled and examined. Both physical examination and laboratory investigation were employed in the study.

Results: The study revealed that cattle in the study area were infested with single (24.5\%) and multiple (2.8\%) ectoparasites with an overall prevalence of $27.3 \%$ (58/212). Overall seven species of ectoparasites which belong to tick (16.0\%), lice $(10.4 \%)$ and mite (0.9\%), were identified. Seven species of ticks which belong to three genera (Boophilus sp., Amblyoma sp., and Rhipicephalus sp.) were identified. Among the species of ticks Boophilus decoloratus (8.0\%), Amblyoma variegatum (4.7\%) and Amblyoma coherens (4.2\%) were the dominant ones in a decreasing order. Among the three species of lice, the most prevalent was Linognathus vituli (4.7\%) followed by Haematopinus euysternus (3.8\%) and Damalina bovis (1.9\%). Psoroptes bovis $(0.9 \%)$ was the only mite species recorded in this study. For all ectoparasites there was no statistical deference $(\mathrm{p}>0.05)$ between the prevalence of any of the ectoparaisite infestation with regard to sex, age and body condition score.
\end{abstract}

Conclusion: The present study revealed a high prevalence and diverse fauna of ectoparasites that could potentially hamper the productivity of cattle in the study area, hence serious attention is warranted.

Keywords: ectoparasites, Ethiopia, prevalence, ruminants

\section{Introduction}

In Ethiopia there are about 38 million cattle, 30 million small ruminants, 1 million camel, 4.5 million equines and 40 million poultry in the country [1]. In the country livestock play vital role in farming system [2]. However, poor health and productivity of animal due to disease has considerably become the major stumbling block to the potential of livestock industry [2]. Now a day parasitism represents a major obstacle to development and utilization of animal resource. In Ethiopia ectoparasites in ruminant causes serious economic loss to small holder farmers, the tanning industry and the country as a whole through mortality of animals, decreased production, down grading and rejection of skin and hide [3-5].

As a result of their activity ectoparasites may have a variety of direct and indirect effects on their hosts. Ectoparasites commonly tick, mite and lice affect the host species by the inflammation and the infection they inflict on the skin [6], and by their effect on the physiology of the animals as well as through transmission of different diseases $[7,8]$. Infestations by

This article is an open access article licensed under the terms of the Creative Commons Attribution License (http://creativecommons org/licenses/by/2.0) which permits unrestricted use, distribution and reproduction in any medium, provided the work is properly cited. ectoparasites significantly affect the quality of hide thereby affecting the economy of Ethiopian farmers as well as international market [9].

Although ectoparasites affect the health, productivity of ruminants, and the economy of the country [9-11]. However, currently there is a paucity of information regarding to ectoparasites of cattle in Bench Maji zone.

The present study was carried out to determine the prevalence and fauna of ectoparasites of ruminants, and associated host-related risk factors in the study area.

\section{Materials and Methods}

Study area description: The study was conducted on Bench Maji Zone, Southwestern Ethiopia from October 2011 to April 2012. The study area was located $550 \mathrm{~km}$ south west of Addis Ababa. The climatic condition of the area is divided into highland (19.3\%), mid land $(51.6 \%)$ and low land $(29.1 \%)$. The average altitude of the district ranges from 1200-2200 m.a.s.l and receives annual rain fall of 1500-2000mm [12].

Study population: Between October 2011 and April 2012, a total of 212 cattle brought to the Bench Maji Zone Veterinary clinic were subjected to detailed examination for the presence of ectoparasites. The 
Table-1. Overall prevalence of ectoparasites in 212 ruminants in Bench Maji Zone

\begin{tabular}{lcc}
\hline Ectoparasite & Total No. Positive & Prevalence (\%) \\
\hline Tick & 34 & 16.0 \\
Lice & 22 & 10.4 \\
Mite & 2 & 0.9 \\
Overall & $\mathbf{5 8}$ & $\mathbf{2 7 . 3}$ \\
\hline
\end{tabular}

Table-2. Species based prevalence of ectoparasites in cattle in Bench Maji Zone

\begin{tabular}{lcc}
\hline Species of ectoparasites & Total No. Positive & Prevalence (\%) \\
\hline Boophilus decoloratus & 16 & 8.0 \\
Amblyoma variegatum & 10 & 4.7 \\
Amblyoma coherens & 9 & 4.2 \\
Amblyoma gema & 4 & 1.9 \\
Rhipicephalus camicasi & 3 & 1.4 \\
Rhipicephalus eversi & 3 & 1.4 \\
Amblyoma lepidium & 2 & 0.9 \\
Linognathus vituli & 10 & 4.7 \\
Hematopinus eurysternus & 8 & 3.8 \\
Damalina bovis & 4 & 1.9 \\
Psoroptus ovis & 2 & 0.9 \\
Overall & $\mathbf{5 8}$ & $\mathbf{2 7 . 3}$ \\
\hline
\end{tabular}

Table- 3. Prevalence of species of ectoparasites by sex, age and body condition.

\begin{tabular}{|c|c|c|c|c|c|c|c|c|c|c|}
\hline \multirow{2}{*}{$\begin{array}{l}\text { Species of } \\
\text { Ectoparasites }\end{array}$} & \multicolumn{2}{|c|}{ Sex } & \multirow[t]{2}{*}{$\chi^{2}(p$-value $)$} & \multicolumn{2}{|c|}{ Age } & \multirow[t]{2}{*}{$\chi^{2}(p$-value $)$} & \multicolumn{3}{|c|}{ Body condition scores } & \multirow[t]{2}{*}{$\chi^{2}(p$-value $)$} \\
\hline & $\begin{array}{l}\text { Male } \\
(n=84)\end{array}$ & $\begin{array}{l}\text { Female } \\
(n=128)\end{array}$ & & $\begin{array}{l}\text { Adult } \\
(n=205)\end{array}$ & $\begin{array}{l}\text { Young } \\
(n=7)\end{array}$ & & $\begin{array}{l}\text { Good } \\
(n=44)\end{array}$ & $\begin{array}{l}\text { Medium } \\
(n=96)\end{array}$ & $\begin{array}{l}\text { Poor } \\
(n=72)\end{array}$ & \\
\hline A. variegatum & $4(4.8)$ & $6(4.7)$ & $0.001(0.980)$ & $10(4.9)$ & - & - & - & $4(4.2)$ & $6(8.3)$ & $4.338(0.114)$ \\
\hline A. lepidium & 1(1.2) & $1(0.8)$ & $0.091(0.763)$ & $1(0.5)$ & $1(14.3)$ & $13.790(0.065)$ & - & - & $2(2.8)$ & - \\
\hline A. gemma & $1(1.2)$ & $3(2.3)$ & $0.364(0.546)$ & $4(2.0)$ & - & - & - & $3(3.1)$ & 1(1.4) & $1.738(0.419)$ \\
\hline A. coherens & $1(1.2)$ & $8(6.3)$ & $3.033(0.857)$ & $8(3.9)$ & $1(14.3)$ & $1.795(0.265)$ & $1(2.3)$ & $2(2.1)$ & $6(8.3)$ & $4.485(0.106)$ \\
\hline B. decoloratus & $6(7.1)$ & $10(7.8)$ & $0.145(1.000)$ & $15(7.3)$ & $1(14.3)$ & $0.471(0.427)$ & $1(4.5)$ & $8(8.3)$ & $7(9.7)$ & $1.016(0.602)$ \\
\hline R. camicasi & $1(1.2)$ & $2(1.6)$ & $0.050(1.000)$ & $3(1.5)$ & - & - & - & $2(2.1)$ & $1(1.4)$ & $0.939(0.625)$ \\
\hline R. eversi & - & $3(2.3)$ & - & $3(1.5)$ & - & - & - & $2(2.1)$ & $1(1.4)$ & $0.939(0.625)$ \\
\hline D. bovis & $2(2.4)$ & $2(1.6)$ & $0.184(0.649)$ & $4(2.0)$ & - & - & $1(2.3)$ & $1(1.0)$ & $2(2.8)$ & $0.715(0.700)$ \\
\hline L. vituli & $3(3.6)$ & $7(5.5)$ & $0406(0.743)$ & $9(4.4)$ & $1(14.3)$ & $1.475(0.291)$ & - & $5(5.2)$ & $5(6.9)$ & $3.025(0.220)$ \\
\hline H. euysternus & $2(2.4)$ & $6(4.7)$ & $0.743(0.483)$ & $8(3.9)$ & - & - & $1(2.3)$ & $6(6.3)$ & $1(1.4)$ & $3.022(0.221)$ \\
\hline$P$. ovis & - & $2(1.6)$ & - & $2(1.0)$ & - & - & - & $1(1.0)$ & $1(1.4)$ & $0.582(0.748)$ \\
\hline Overall & $21(25)$ & $50(39.1)$ & & $67(32.7)$ & $4(57.1)$ & & $6(9.1)$ & $34(35.4)$ & $33(45.8)$ & \\
\hline
\end{tabular}

study population included indigenous cattle (84 male and 128 female) of different age, sex and body condition categories. The age of animals was grouped as young (between 1 and 3 years) and adults ( $\geq 3$ years) according to the classification method used by Bitew [13]. Likewise, the body condition scores (good, medium and poor) were classified based on the criteria set by Nicholson and Butterworth [14].

Protocol design and method: Both physical and parasitological examinations were employed. Skin scrapings from suspected cases of mange were collected and preserved in 10\% formalin. Mites were made to be released from scabs and crusts after addition of $10 \% \mathrm{KOH}$ on the specimens according to the procedure described by Soulsby [15]. Ticks and lice were collected in $70 \%$ alcohol. Identification of the collected ectoparasites was carried out by the aid of stereo- and compound microscope using identification keys set by Wall and Shearer [16] and Soulsby [15].

Statistical analysis: The collected data was analyzed by a statistical software namely, SPSS version 20 . Prevalence was determined by the formula described by Thrusfield [17] as the rate of number of infested animals and total number of animals in the population. Associations between explanatory variables (age, sex and body condition score) and prevalence was done by chi-square $\left(\dot{\div}^{2}\right)$ test. In all analysis, 95\% confidence intervals and $P<0.05$ were set to indicate significance.

\section{Results}

Overall prevalence of ectoparasites: Of the 212 cattle examined in this study, 58 (27.3\%) were found infested with one or more species of ectoparasites, which accounts for $16.0 \%, 10.4 \%$ and $0.9 \%$ for tick, lice and mite respectively (Table-1).

As indicated in Table-2, overall four genera comprising seven species of ticks, three genera consisting of three species of lice, and a single species of mites were identified in this study. Among the ticks, Boophilus decoloratus (8\%), Amblyoma variegatum (4.7\%) and Amblyoma coherens (4.2\%) were the most prevalent, and the least identified tick species was Amblyoma lepidium (0.9\%). In this study, out of the three species of lice recorded Linognathus vituli (4.7\%) was the most prevalent followed by Hematopinus euysternus (3.8\%) and Damalina bovis (1.9\%).With regard to mites, Psoroptus ovis was the only mite species identified with a prevalence of $0.9 \%$.

Sex wise prevalence of ectoparasites: The overall prevalence of external parasite infestation in male and female animals was $25.0 \%$ and $39.1 \%$, respectively. The difference in the prevalence in male and female animals was not statistically significant $(p>0.05)$. In both sexes $B$. decoloratus and A. variegatum were the dominant ectoparasites (Table-3).

Age wise prevalence of ectoparasites: The overall prevalence of ectoparasites in the adult and young age groups was $32.7 \%$ and $57.1 \%$, respectively. Nonetheless, the present study revealed no statistical difference $(p>0.05)$ in the prevalence of the various species of ectoparasites between the two age categories (Table-3).

Prevalence of external parasites by body condition: The overall prevalence of external parasites in animals with good, medium, and poor body condition was $9.1 \%, 35.4 \%$ and $45.8 \%$, respectively. In all the three examined hosts, there was no disparity in harboring 
any of ectoparasite infestations between the different body condition categories (Table-3).

\section{Discussion}

The result of the present study showed a wide range of single and multiple ectoparasites infestation with an overall prevalence of $27.3 \%$ in the study area. This result was lower than the report of by Tadesse et al. [18] (73.3\%) from Ethiopia, Islam et al. [19] (65.5\%) from Bangladesh. Variation in geographical locations, climatic conditions, and management practices in the different study areas might have contributed for the disparity in prevalence.

In this study tick (14.5\%) infestation was the outstanding ectoparasites followed by lice $(12.1 \%)$ and mite $(3.4 \%)$. This finding was in agreement with earlier studies on ruminants $[11,20,21]$ who reported the predominance of ticks. In contrast to our finding, a higher prevalence of $39.6 \%$ [18] and $64.07 \%$ [22] of ticks has been reported. The lower prevalence of ticks in cattle in the present study area could be attributed to the relatively good access to veterinary services, and it could also be due to the long dry season of the study period, because tick infestations tend to decrease during the dry season compared to the wet seasons [23]. Climatic determinants of the study areas such as humidity and prolonged sunlight favor the multiplication and maintenance of the parasite in the environment [24].

Out of the seven species of ticks recorded, the most prevalent was $B$. decoloratus $(8.0 \%)$ followed by $A$. variegatum (4.7\%). The dominance of $B$. decoloratus followed by $A$. variegatum in cattle was previously reported [2,25-28]. The dominance of Boophilus species over Amblyoma species was because of the dependence of native distribution of ticks on the distribution of host species and climatic condition [29]. As observed by Endale [30] there existed no statistical significant difference $(p>0.05)$ in the prevalence of ticks between the different sex, age, and body condition score categories. This could be related to the management system where animals are allowed to graze together in communal fields in the mixed farming system of the study area.

The overall prevalence of lice recorded in the present study was $10.4 \%$. Our finding was in consent with the result of Tadesse et al. [18] who reported a prevalence of $9.5 \%$. On the contrary, this result was in disagreement with the finding of Rony et al. [22], Nigatu and Teshome [21] (63.5\%). These disparities could be attributed to differences in the agro-ecology, climatic condition, and sample size used in the study areas. Out of the three species of lice recorded in cattle L. vituli $(4.7 \%)$ was outstanding followed by $H$. euysternus $(3.8 \%)$ and D. bovis (1.9\%). Dominance of $L$. vituli followed by $H$. euysternus was also reported previously [21,22,31]. In general the lice species recorded in this study have commonly been identified in ruminant in Ethiopia [18, 21] and elsewhere [22]. In this study there was no significant difference $(p>0.05)$ in the prevalence of lice infestation among the different sex, age and body condition categories in the three hosts examined. Similar observation was made by Nigatu and Teshome [21]. This might be due to the management practice in the study area where animals are kept together which facilitates transmission of lice by direct contact [6].

The overall prevalence of mite in cattle was $0.9 \%$ and $P$. ovis was the only mite species identified in the area. Our finding was in close agreement with the report of Tadesse et al. [18] (0.4\%). On the contrary, prevalence of mites as high as $95.5 \%$ [21] was reported from Western Ethiopia. This discrepancy might be due to difference in the ideal macro and micro environment (high temperature, humidity and sun light) in the study areas which favors the breeding and multiplication of mite [32]. Although prevalence of $P$. ovis was lower in this study its potential to cause serious skin lesions should not be undermined [32]. There was no significant dispersion in the infestation of animals by mites with regard to sex, age and body condition categories in ruminants. Age and sex are not determinant factors in the infestation of mites [8].

\section{Conclusion}

Overall ruminants in Bench Maji zone in Southwest Ethiopia were found to be infested with diverse ectoparasitic fauna implying their effects on productivity of these animals and on the economy of farmers and the country at large. Hence, Very good veterinary services and management practice should be put in the place to control infestations of these valuable animals. Moreover, further epidemiological investigations that consider different agro-ecology and management system is warranted for appropriate control of ectoparsites.

\section{Authors' contribution}

Tesfaheywet Zeryehun Shiferaw implemented study design, involved in the acquisition of data and data analysis. Tesfaheywet Zeryehun Shiferaw and Simeon Haile Onu drafted the manuscript. Both authors revised the manuscript, read and approved the final manuscript.

\section{Acknowledgements}

The authors would like to thank the Bench Maji Zone Veterinary Clinic and Parasitology Laboratory staff members for their provision of necessary materials and the help rendered during the study period.

\section{Competing interests}

Authors declare that they have no competing interests.

\section{References}

1. Central Statistic Authority (CSA), (2011) Federal Democratic Republic of Ethiopia, Agricultural sample enumeration statistical abstract.

2. Mekonen, B., Hussen, I. and Bedane, B. (2001) The distribution of Ixodid tick in central Ethiopia. Onderstepoort J. Vet. Res., 68: 243-251.

3. Regassa, A. (2001) Tick infestation of Borana cattle in the 
Borana Province of Ethiopia. Onderstepoort J. Vet. Res., 68:41-45.

4. Tefera, S. and Abebe, W. (2004) A study on ectoparasites of sheep and goat in eastern part of Amhara region north east Ethiopia, (DVM thesis) Faculity of Veterinary Medicine, Addis Ababa Unversity, Ethiopia. 17- 23.

5. Tikit, B. and Addis, M. (2011) Distribution of Ixodid Ticks on Cattle in and Around Holeta Town, Ethiopia. Global Vet., 7(6) 527-531.

6. Taylor, M.A., Coop, R.L. and Wall R.L. (2007) Veterinary parasitology, $3^{\text {rd }}$ edition by Black well publishing Ltd., UK. 874.

7. Wall, R. and Shearer, D. (2001) Veterinary ectoparasites biology pathology and control, 2nd edition, Black well science Ltd., UK. 262.

8. Bekele, J., Tarikua, M. and Abebe, R. (2011) External parasite infestation in small ruminants in Wolmera district, Oromia region, Central Ethiopia. J. Anim. Vet. Adv., 10: 518523.

9. Bekele, T. (2002) Study on seasonal dynamics of tick of Ogaden cattle and individual variation in resistance to ticks in Ethiopia. Ethiop. J. Vet. Med., 49: 285-288.

10. Ayele, S. Asegid, W., Abera, M.A., Ahmed, M.M. and Belachew, H. (2003) Livestock marketing in Ethiopia. A review of structure, performance and development initiatives. Socio economic and policy research work paper. Nairobi Kenya, 52:121.

11. Yacob, H.T., Netsanet, B. and Dinka, A. (2008) Prevalence of major skin disease in cattle, sheep and goat at Adama veterinary cilinic, Oromia regional state, Ethiopia. Addis Ababa University, Ethiopia. Rev. Méd. Vét., 159: 455-461.

12. Mizan Teferei Regional Veterinary Laboratory (MTRVL) (2008) Mizan Teferi Regional Veterinary Laboratory annual report and result record.

13. Bitew, M., Amedie, Y., Abebe, A. and Tolosa, T. (2011) Prevalence of bovine trypanosomosis in selected areas of Jabi Tehenan district, West Gojam of Amhara regional state, Northwestern Ethiopia. Afr. J. Agri. Res., 6: 140-144.

14. Nicholson, M. and Butterworth, T. (1996) A guide to body condition score in zebu cattle international livestock center for Africa, Addis Ababa, Ethiopia.

15. Soulsby, E.J.I. (1982) Helminths, Arthropod and Protozoa of Domesticated Animals, 7th edition. Bailliere, Tindall and Cassell Ltd. 136-346, 365-491 and 763-778.

16. Wall, R. and Shearer D. (1997) Veterinary Entomology, 1st edition, Chapman and Hall. London, UK. 265 and 290.

17. Thrusfield, M. (2005) Veterinary epidemiology, 3rd edition, London: Black well science Ltd. 32.

18. Tadesse, A., Fentaw, E., Mekbib, B., Abebe, R., Mekuria, S. and Zewdu, E. (2011) Study on the prevalence of ectoparasite infestation of ruminants in and around Kombolcha and damage to fresh goat pelts and wet blue (pickled) skin at Kombolch Tannary, Northestern Ethiopia. Ethiop. Vet. J., 15:87-101.

19. Islam, M.S., Rahman, S.A., Sarker, P. and Anisuzzaman, M.M.H. (2009) Prevalence and population density of ectoparasitic infestation in cattle in Sirajgonj district, Bangladesh. Bangl. Res. Pub. J., 2: 332-339.

20. Amsalu, Y. (2011) Identification of major Ixode tickes on cattle in and around Haramaya town, Eastern Hararge, (DVM thesis), Haramaya University, Ethiopia.

21. Nigatu, K. and Teshome, F. (2012) Population dynamics of cattle ectoparasite in western Amhara national regional state, Ethiopia.J. Vet. Med. Anim. Helth., 4:22-26.

22. Rony, S.A., Mondal, M.M.H., Begum, N., Islam, M.A. and Affroze, S. (2010). Epidemiology of ectoparasitic infestations in cattle at bhawal Forest area, Gazipur. Bangl. $J$. Vet. Med., 8: 27-33.

23. Shiferaw, D. and Abebe, G. (2006) Cattle tick dynamics in different agro-ecological zones of Wolayta, southern Ethiopia. Ethiop. Vet. J., 10: 85-99.

24. Sajid, S.M., Iqbal, Z., Khan, N.M. and Muhammad, G. (2008) Point Prevalence of Hard Ticks (Ixodids) Infesting Domestic Ruminants of Lower Punjab, Pakistan. Int. J. Agri. Biol., 10: 349-51.

25. Alekaw, S. (1998) Distribution of tick and tick-born disease at Metekel Ranch. Ethiop. Vet. J., 4: 30.

26. Solomon, G., Nigist, M. and Kassa, B. (2001) Seasonal variation of tick on calves at Sebeta in Western Shoa Zone. Ethiop. Vet. J., 1: 17-30.

27. Behailu, A. (2004) A Study on tick and tick born protozoansin cattle at Assela, Arsi zone, (DVM thesis), Addis Ababa University, Ethiopia.

28. Fantahun, B. and Mohamed, A. (2012) Survey on the Distribution of Tick Species in and Around Assosa Town, Ethiopia. Res. J. Vet. Sci., 5: 32-41.

29. Pergam, G., Hoogsstraal, H. and Wassef, H. (1981) Tick Argasidae, Ixodidae of Ethiopia, Distribution, ecology and host relationship of species infecting livestock. Bull. Entamo. Res., 71:339-359.

30. Endale, B. (2006) A survey on tick of cattle in Ambo area, western Ethiopia (DVM thesis), Addis Ababa University, Ethiopia.

31. Kumssa, B. and Bekele, M. (2008) Lice infestation on cattle in Endegagin district, South Ethiopia.Species composition prevalence and seasonal pattern. Bull. Anim. Helth. Prod. Afr., 58:213-222.

32. Radostitis, O.M., Gay, C.C., Hinchcliff, K.W. and Constabel, P.D. (2008) Veterinary medicine, a text book of disease of cattle, horses, sheep, pigs, and goat. 10th edition. Edinburgh, Saunders Elsevier. 1585-1612. 